\title{
Entre golpes e dispositivos: Foucault, Certeau e a constituição dos sujeitos
}

\author{
Between blows and rearrangements: Foucault, Certeau and the \\ constitution of the subjects
}

\author{
André Bocchetti \\ andreb.ufrj@gmail.com \\ Professor Adjunto \\ Universidade Federal do Rio de Janeiro \\ Rua Barata Ribeiro, 531/701 - Copacabana \\ 22040-001 - Rio de Janeiro - RJ \\ Brasil
}

\begin{abstract}
Resumo
A análise procura aproximações e distanciamentos entre alguns dos principais conceitos abordados por Michel de Certeau e Michel Foucault, construindo uma proposta que os aproxime no estudo da constituição dos sujeitos. Foi considerada a obra $A$ invenção do Cotidiano: 1. Artes de fazer observada a partir de contribuições de Foucault associadas à análise do discurso e à constituição moral do sujeito. As discussões apontam para uma analítica na qual discursos e práticas cotidianas são contemplados, criando reposicionamentos nos jogos de verdade constituídos a partir das produções estratégicas e táticas. Mecanismos de governo passam a ser analisados em sua capacidade de "apropriação" dos saberes locais. Os objetos constituídos nas relações de poder (instituições, mecanismos, discursos) - e não apenas seus usos - são considerados na medida em que interferem na utilização dos saberes socialmente constituídos. A partir de tais contribuições, apresenta-se uma proposta analítica que encontra nas práticas cotidianas e discursivas suas bases.
\end{abstract}

\section{Palavras-chave}

Michel de Certeau; Michel Foucault; Discurso.

\begin{abstract}
The article points at similarities and differences in some of the main concepts used by Michel de Certeau and Michel Foucault, and presents a proposal to bring the two authors closer to each other in their study of the constitution of subjectivities. The work under study is The practice of everyday life, which is considered vis-à-vis Foucault's contributions on discourse analysis and on the moral constitution of the subject. These discussions point at an analytic exam in which discourses and daily practices are approached, leading to rearrangements in the games of truth, as a result of their strategic and tactical products. Governmental mechanisms are then analyzed in terms of their ability to "accroach" local forms of knowledge. Objects that have been established in the midst of power relations (institutions, mechanisms, discourses) - and not only their uses - are examined inasmuch as they interfere in the use of socially-produced forms of knowledge. From these contributions, the article presents an analytic proposal based on daily and discursive practices.
\end{abstract}

\section{Keywords}

Michel de Certeau; Michel Foucault; Discouse. 
O nascimento daquilo que, já em seu colapso, viríamos a chamar modernidade nomearia um elemento estranho ao qual a filosofia, a história, a sociologia ou a psicologia não cessariam de inventar: o sujeito. Do desmantelamento do "ser em si" em Kant - nesse exercício filosófico primordial que é o de "prevenir a razão de ultrapassar os limites daquilo que é dado na experiência, dirá Foucault (1995, p. 233) -, passando pela ascensão moderna das racionalidades do Estado ou, mais recentemente, pelas investidas sobre a subjetividade características do "modelo capitalístico" contemporâneo - denunciadas, entre outros, por Felix Guattari (1985) -, são vários os movimentos realizados nos mais diversos campos de saber que as sociedades foram capazes de inventar, pelos quais aquilo que somos passaria, necessariamente, a residir de uma certa maneira em uma individualidade passível de análise e, portanto, de delimitação e intervenção. Sobretudo a partir do século XVIII, seriam densos e contínuos os investimentos filosóficos e científicos - ora na figura de uma pedagogia das relações, ora na produção de uma estética de si - que centrariam sua produção naquilo que deveria, essencialmente, nos constituir.

Durante o século XIX, com as críticas de Nietzsche, e até aqui, viu-se um importante deslocamento, porém - notavelmente no campo da filosofia e da história -, dos questionamentos acerca daquilo que viria a produzir a subjetividade. As questões "O que existe na essência dos indivíduos? O que deve ser buscado para encontrá-la?" sofreriam, a partir daí, uma importante inversão - atrelada à crítica de uma suposta essencialidade do sujeito -, sendo então abandonadas em honra da tentativa de compreensão, por grande parte dos filósofos e historiadores, dos elementos que constituem as possibilidades de nos tornarmos aquilo que somos. Historicizada, a subjetividade seria então posta em cheque, como elemento resultante de cruzamentos de saberes, poderes, estratégias. Indubitavelmente, tais questionamentos encontrariam em Michel Foucault e Michel de Certeau dois de seus grandes signatários. Apresentar um esboço do que poderia se constituir por meio de uma proposta analítica fundada no entrelaçamento do pensamento desses autores é o que justifica este trabalho.

A aproximação entre os autores está longe de ser consensual. Certeau dedicaria uma parte de sua obra à elucidação de sua aproximação e, principalmente, suas diferenças em relação ao legado foucaultiano. Sobre Foucault, o autor diria:

Mostrando, num caso, a heterogeneidade e as relações equívocas dos dispositivos e das ideologias, ele constituiu em objeto histórico abordável esta região onde procedimentos tecnológicos têm efeitos de poder específicos, obedecem a funcionamentos lógicos próprios e podem produzir uma alteração fundamental nas instituições da ordem e do saber. Resta ainda perguntar o que é que acontece com outros procedimentos, igualmente infinitesimais, que não foram privilegiados pela história (CERTEAU 2008, p. 116).

É justamente em termos de perspectiva analítica que Certeau, repetidas vezes em seus textos, irá assinalar os limites do pensamento de Michel Foucault dos quais iria se desvencilhar. Ao olhar foucaultiano sobre o poder, a obra 
certeauniana contraporia uma análise dos golpes que anulam seus efeitos (CHARTIER; HÉBRARD 1998) - um olhar, portanto, que procuraria contrapor certa passividade do sujeito frente aos sistemas que procuram discipliná-lo à possibilidade de criação advinda de uma forma ativa de consumo, uma "antidisciplina" nas palavras do próprio Certeau.

Dois pontos, no entanto, merecem especial atenção no que se refere a tal posicionamento. O primeiro deles remete à inegável aproximação entre a produção dos dois autores. Levantando questões diretas à dinâmica do poder na perspectiva de Foucault, Michel de Certeau não deixará de se aproximar de uma analítica que considera a existência e manutenção das disciplinas e dos instrumentos a ela associados - sobretudo o olhar institucional incessante, ao qual faz sucessivas referências em sua obra (2008, p. 173, 237, 280).

Além disso, e principalmente, parece necessário ponderar-se que, durante a construção de sua crítica ao legado foucaultiano, sobretudo naquela levada a cabo em sua obra L'invention du quotidien: arts de faire, ${ }^{1}$ os questionamentos de Certeau referem-se às reflexões apresentadas no livro Surveiller et punir, ${ }^{2}$ a ele limitando-se. Historicamente justificável, ${ }^{3}$ tal analítica não poderia considerar a série de publicações de Foucault que se seguiria, inclusive, com importantes revisões de perspectiva, o que certamente traria novas possibilidades de discussão. ${ }^{4}$

Diante de tal contexto, e considerando as contribuições realizadas por ambos os autores nas questões relativas à constituição dos sujeitos, parece profícua a realização de uma empreitada analítica que reconsidere algumas aproximações e distanciamentos das reflexões por eles trazidas. Há movimentos paralelos em Foucault e Certeau no que diz respeito à analítica sobre o modo como os sujeitos se constituem e operam. $\mathrm{E}$, se é evidente que uma parte da analítica foucaultiana estaria centrada nos mecanismos disciplinares e, assim, no âmbito daquilo que Certeau chamaria de estratégias, é também visível o espaço de liberdade e criação evidenciado (e necessário) nos estudos de Foucault.

Parece que o olhar sobre os usos e as práticas cotidianas, evidentemente marcantes nos textos de Certeau, permite reflexões importantes que, associadas a algumas conceituações de Foucault - a maior parte delas incipientes ou inexistentes em Surveiller et punir - abrem espaço para novas possibilidades analíticas acerca da constituição dos sujeitos. Além disso, certa complementaridade (sempre inventada) entre ambos os legados pode ser profícua ao esboço inicial de uma teoria da ação que não se constituiu

\footnotetext{
${ }^{1}$ Traduzida no Brasil como A invenção do cotidiano: 1. Artes de fazer, por Ephraim Ferreira Alves, em 1994. 2 Traduzido como Vigiar e Punir: Nascimento da Prisão, por Raquel Ramalhete, em 1987.

${ }^{3}$ A publicação de Surveiller et punir, em 1975, causaria certa inquietação dos historiadores e culminaria em seu silêncio. A microfísica do poder apresentada por Foucault será lida, a partir daí, como uma visão niilista, e as críticas seriam abundantes. Também por isso, a obra alcançaria rapidamente uma circulação internacional, justificando análises e pronunciamentos efetivos da comunidade acadêmica (DEFERT 2002).

${ }^{4}$ De fato, a produção de Foucault está repleta de revisões analíticas e mudanças de perspectiva, levando alguns autores, como Morey (apud VEIGA-NETO 2004), a dividir tal legado em três eixos ontológicos. O autor considera que toda a obra foucaultiana estaria voltada à compreensão da constituição dos sujeitos, mas em vertentes distintas que, embora não segmentadas, precisam ser consideradas, pois definiram as discussões principais abordadas nos livros escritos pelo autor. Assim, uma parte dessas obras seria dedicada à compreensão do que somos como sujeitos de conhecimento; outra estaria associada à discussão de como nos tornamos sujeitos constituídos pela moral; e outra, finalmente, dedicada à discussão sobre como nos tornamos sujeitos de ação, vertente na qual estaria inserida a obra Surveiller et punir.
} 
definitivamente em nenhum dos autores. Ensaiar algumas dessas aproximações e propor algumas bases, ainda bastante frágeis, para um modelo de análise que considere a produção de ambos os autores é o objetivo dessas linhas.

\section{Sobre percursos e genealogias}

Há algo profundamente estremecido no estatuto da verdade que a modernidade, após profundas inversões na constituição do pensamento religioso, pôde constituir. Um estremecimento, em primeiro lugar, causado por sua historicização - pela constituição de saberes que, em Foucault, são tomados como "agenciamento daquilo que uma época pode dizer (seus enunciados) e ver (suas evidências)" (DROIT 2006, p. 29). Queda, ainda, causada pela instituição de uma alteridade múltipla, capaz de ao mesmo tempo pôr em cheque a universalidade e impedir que, em seu lugar, se forme um Outro, uno e, por isso, igualmente limitado.

De um lado, jogos de verdade, e a necessidade analítica de se compreender como, em determinados contextos, os saberes se movem para produzir aquilo que é socialmente pensável. De outro, olhar sobre as práticas, sobre as maneiras pelas quais nos apropriamos ou subvertemos aquilo que nos chega e tenta nos controlar, nos moldar, nos produzir (CHARTIER 2002, p. 160). Um Foucault, outro Certeau. Em ambos o interesse em compreender as possibilidades de multiplicidade, de heterogeneidade; dos outros, enfim, que se singularizam naquilo que, cotidianamente, produzem.

Há, pois, que se olhar com desconfiança para os modelos - aqueles que uma história recorrente ${ }^{5}$ utilizaria para colocar em uma linearidade duvidosa os saberes legitimados por uma época. Em seu lugar, algumas possibilidades: com Foucault, o desejo do genealogista - explicar a existência dos saberes e suas transformações, situando-os no interior das relações de poder; em Certeau, o prazer do relato, consciente de seus limites - já que a escrita é em si uma prática a ser analisada - mas mesmo assim desejoso em evidenciar as apropriações que são feitas desses saberes quando eles são postos em operação.

Trata-se, portanto, de uma análise dos usos de tais saberes, ora posicionados no plano da institucionalização e da legitimação, ora observados nos espaços que a ambas escapam. Não seria isso que Foucault estaria fazendo ao discutir, por exemplo, a maneira como se procurou constituir, a partir do século XVIII, um olhar legitimado sobre aquilo que se chamaria população, relativizando-se assim o até então primordial olhar sobre o soberano, mediante o deslocamento de um conjunto de saberes associados à família e aos governantes? Certeau não estaria, em outro plano, fazendo algo similar, ao considerar as maneiras pelas quais o leitor se apropria e inverte aqueles textos dos quais se aproxima, construindo espaços para uma leitura plural?

Olhares com posicionamentos distintos, que não deixam de considerar, no entanto, os diversos lugares de produção dos saberes. Seria impossível a

\footnotetext{
${ }^{5} \mathrm{O}$ termo "história recorrente" refere-se a uma história "que se esclarece pela finalidade do presente, uma história que parte das certezas do presente e descobre, no passado, as formações progressivas da verdade" (MACHADO 2006, p. 44).
} 
Certeau uma discussão sobre a produção do conceito de cidade e urbanidade sem considerar que, formalmente - e institucionalmente, pois - tal ideia viria a ser constituída atrelada à de um espaço próprio, estabelecido sobre uma certa atemporalidade. Da mesma forma, a análise foucaultiana em torno da constituição dos saberes vem associada à questão de sua emergência, o que significa analisar as condições para seu aparecimento e as relações que se estabelecem em sua base, seja entre instituições, processos ou comportamentos individuais (FOUCAULT 2008, p. 50).

O que resta ao estudioso, pois? Em síntese, uma análise das condições de possibilidade de produção e apropriação de tais saberes. Condições sempre encontradas no interior de espaços de luta e enfrentamento. Espaços onde subsistem saberes perecíveis e consumos impensáveis, e onde se constituem enunciados que, também por meio das práticas, tornam-se legitimáveis e, portanto, úteis como instrumento de governo. Em tal arena, a contraposição certeauniana (e sempre dinâmica) entre estratégias - manipulação das relações de força por um sujeito que se constitui em lugar próprio - e táticas - ação calculada que é determinada pela ausência de um próprio (CERTEAU 2008, p. 100) - encontra seus produtos. Também aqui, a produtividade do poder encontra suas mais diretas consequências.

Mas há diferenças analíticas fundamentais quanto ao lugar do poder. Certeau procura os espaços que Ihe escapam; Foucault, as relações que desviam seu fluxo. Inversão de base conceitual: de lugar a partir do qual se atua - não questionado na crítica certeauniana -, o poder na ótica foucaultiana é lido, sempre, como ato. Uma "ação sobre ações" (FOUCAULT 1995, p. 242) que não apenas interdita e controla, mas também (e principalmente) produz e incita. Seria preciso, pois, um olhar um tanto diferenciado para as estratégias e táticas, que aqui estariam diretamente associadas às conformações das relações de poder que se desenvolvem em um determinado contexto, e não a sua presença ou ausência.

Se a verdade de uma época é uma "mistura de nonsense e poder" (CERTEAU 2008, p. 71), há que se considerar os mecanismos e desvios evidentes nas relações de força para colocar a universalidade do conhecimento em cheque. Seja por meio de uma análise das disciplinas ou da construção de narrativas das antidisciplinas, será necessário contemplar os movimentos que constituem os saberes, situar suas trilhas, evidenciar os espaços que ao seu redor se constituem. O genealogista tem, também, um pouco de caçador.

\section{Qual o lugar do discurso?}

É necessário precisar melhor o objeto dessa caça. De qualquer modo, trata-se de um olhar sobre os enunciados de uma época - aquilo que lhe produz ou lhe escapa - e sobre as operações que seu estabelecimento permite ou não. Primeiramente, as táticas: "sua síntese intelectual tem por forma não um discurso, mas a própria decisão, ato e maneira de aproveitar a ocasião" (CERTEAU 2008, p. 47). Funcionamento paralelo à produção discursiva, se a tomarmos como a construção de conjuntos de signos que remetam a representações sociais abrangentes. 
Com Foucault, outro olhar sobre o discurso, agora como "práticas que formam sistematicamente os objetos de que falam" (FOUCAULT 2008, p. 55). Algo, pois, de aparentemente não-discursivo na formação dos enunciados. Incoerência, no entanto, que se dissipa ao se considerar que tais práticas discursivas nascem, justamente, por meio da operação das instituições, mas também dos comportamentos, das formas de transmissão e de difusão enunciativa, evidenciadas nos diversos espaços sociais.

Retornemos às táticas, agora com a intenção de posicioná-las no interior desses discursos-práticas que se espraiam e encontram, em diferentes espaços, condições para emergir como saberes legitimados. Tomando-os em suas possibilidades de dispersão, torna-se difícil pensar em espaços que estejam alheios à sua constituição. A própria apropriação tem algo de reprodução, seja dos enunciados, das práticas que as engendram ou das condições de possibilidade de uma época. É preciso, pois, considerá-la, estando ou não associada às práticas cotidianas, também como um campo de lutas, e para isso é fundamental que se compreenda a maneira pela qual as enunciações, na especificidade de seu alcance, se constituem.

De um lado, pois, a produção discursiva que, enquanto tipicamente estratégica, nasce da reivindicação de um lugar próprio de onde se enuncia e de onde emergem suas práticas. Para constituir sua unidade, os discursos se fundamentam na produção da unidade dos objetos de que falam, no estilo a partir do qual são apresentados (forma, tipo de encadeamento de idéias, modo de apresentação), na manutenção e permanência de determinados conceitos e na produção da identidade de determinadas temáticas a eles importantes (FOUCAULT 2008). Quanto às táticas, importa compreendê-las também no interior dessa produção. Elas operam nesse sistema, instaurando apropriações que remetem a um momento, um espaço e um contrato com o outro (CERTEAU 2008, p. 40). Mas o fato de não reivindicarem um lugar de enunciação não significa que este jamais será definido. Da mesma maneira, a ação estratégica compreende outra maneira de se apropriar de tais produções locais - também as subverte, também as incita a outros usos, e essa parece uma inversão importante trazida pela reflexão foucaultiana. Auge da dinâmica tática-estratégia, com suas inversões e reposicionamentos.

Estamos aqui - apenas para trazer uma exemplificação analítica - no campo daquilo que Foucault chamaria governamentalidade: "táticas de governo que permitem definir a cada instante o que deve ou não competir ao Estado, o que é público ou privado, o que é ou não estatal etc." (FOUCAULT 2004, p. 292). A invenção do inquérito é um exemplo emblemático. A liquidação de uma contenda, durante toda a Idade Média feita diretamente entre indivíduos, será incorporada na razão de Estado a um modelo que Ihe transfere o poder de julgar, constituindo elementos jurídicos até então inexistentes, como o procurador, a infração e a multa (FOUCAULT 2005a). Movimento, pois, de incorporação e alterações de saberes e práticas, que permitiriam uma nova configuração das estratégias de governo, mas, igualmente, modificariam as formas de se exercer a prática judiciária. Com elas, indubitavelmente, surgiriam novas formas de 
apropriação e resistência - novos usos, jamais elucidáveis sem a determinação dos jogos de verdade que formam os sistemas nos quais estão inseridos.

Eis, portanto, um cenário analítico que parece profícuo ao delineamento das condições de saberes e poderes que se constituem em espaços sociais específicos, influenciando subjetividades. Ato ou discurso, consumo ou governamentalização? Termos de um percurso a ser mapeado que, em seu cerne, encontra o jogo infinito das táticas e estratégias. Relativização fundamental do "mais forte" e do "mais fraco", que redefinem suas posições, que tomam lugares e assumem legitimações.

Tais sistemas enunciativos, de grande complexidade, não são contínuos, e o "movimento browniano" (CERTEAU 2008, p. 47) das táticas encontra lugar, igualmente, nas produções discursivas, compostas de apropriações e abandonos. Descontinuidades que as grandes narrativas tentariam esconder, mas cujo mapeamento se constituiria em atividade fundamental para a compreensão das estratégias pelas quais se inventa uma historicidade. Assim é na analítica dos relatos, bricolagens narrativas que com seus retalhos formam mitos, e igualmente na análise da formação das identidades nacionais, dos sistemas econômicos ou do discurso pericial.

Uma história das ficções, duráveis ou cotidianas. Como o fez Certeau ao analisar a escrita, nela encontrando o caráter ficcional da produção da obra, da passividade do leitor ou da hierarquia dos saberes. Como o fez Foucault ao constituir uma narrativa da anormalidade, de sua institucionalização, controle e encarceramento. Mas, igualmente, uma história das inversões e criações, da utilização, como na oralidade ou nas táticas de leitura.

As práticas se constituem em sua narratividade, assim como o sujeito se elabora no interior dos enunciados com os quais opera e nos usos que deles faz. A tese dessas linhas é que um exercício analítico valioso consiste em abordar, justamente, esses dois espaços. Produções e usos sob um olhar que os considere na multiplicidade das táticas de apropriação e consumo e, igualmente, nas descontinuidades da produção estratégica, nos enunciados que constrói e nos mecanismos a partir do qual tenta fazê-los operar.

\section{Entre habilidades e liberdades}

A questão da verdade é uma questão de visibilidade, em dois sentidos. Ela se forma, de um lado, pela enunciação de saberes visíveis, que se estabelecem no interior de jogos de verdade. E procura se manter por meio de outra visibilidade, a dos indivíduos, submetidos (mas não submissos) ao olhar disciplinar que é, ao mesmo tempo, o dos mecanismos institucionalizados mas, também, o do olhar sobre si mesmo da intimidade e da tomada da consciência.

Tornar visível, pois, será também constituir espaços éticos - seja no olhar sobre o outro ou pelo cuidado de si - submetidos à mesma dinâmica de forças que permitem que se estabeleçam, nos demais termos das relações sociais, os lugares das estratégias e as trilhas táticas. O olhar sobre si mesmo, pelo exame das próprias práticas e pela busca do verdadeiro, se tornaria, desde os gregos, um espaço de constituição de técnicas e intervenções. Inicialmente associado 
a um privilégio dos homens livres da polis, ele iria se constituir, já nos séculos iniciais da era cristã, em um exercício para a vida toda, tendo como base a condução do indivíduo à verdade (FOUCAULT 2005b).

A intensificação do olhar sobre si e sobre o outro constitui espaços fundamentais a serem governamentalizados, e as técnicas de governo dos indivíduos - e agora de suas consciências - tomarão vulto no espaço social. Da confissão religiosa às sessões terapêuticas, uma série de estratégias viria a se constituir para que os indivíduos, de maneira mais efetiva, pudessem analisar a si mesmos.

Nova relativização de uma suposta autonomia das práticas cotidianas. Será necessário, pois, encarar a apropriação dentro dos espaços e tentativas de transformá-la em uma ascese governável. As formas de consumo não estão alheias a esses investimentos sobre as relações do sujeito consigo mesmo que já com os gregos se tornariam objeto de problematização. A leitura, por exemplo esse lugar de invenção de outros textos (CERTEAU 2008, p. 264) - não deixará de ser, desde Sêneca, uma importante prática de si, para a qual o discípulo deveria se dedicar, alternadamente com a escrita, de maneira aceitável para o seu mestre (FOUCAULT 2006).

Considerar o que há de visibilidade nas práticas invisíveis, para que sua invisibilidade seja de fato contemplada. O visível, essa produção histórica, é antes de tudo ficcional - provavelmente por isso a construção de séries estatísticas será tão amplamente questionada por Certeau e Foucault - e não está associado apenas aos mecanismos disciplinares de natureza institucional e de vigilância social. O sujeito aprende a sê-lo, também, nas bases possíveis (e mais ou menos governáveis) de suas invenções cotidianas. As artimanhas individuais o são, também, dentro de espaços possíveis e historicamente pensáveis - e por isso cozinhar, costurar ou relatar trazem consigo a luta cotidiana do governo e do consumo.

Onde estarão, então, os espaços de liberdade? Provavelmente, nos mesmos interstícios que permitiram a construção dos grandes enunciados. Com a ajuda de Foucault e Certeau, será possível, talvez, uma microfísica das visibilidades e invisibilidades, que garanta o olhar sobre as heterogeneidades, mas que seja igualmente capaz de encontrar as homogeneidades dos discursos e das produções cotidianas. Algo a ser feito, por um lado, pela análise dos saberes institucionalizados e, por outro, pelo olhar sobre as práticas. Em ambos, porém, com o desejo de se compreender os espaços da alteridade, a relação com os outros e os termos da formação de um Outro, único, sempre tão perigosa quanto a da verdade universal e a dos saberes eternamente aceitáveis.

A justa medida da alteridade - entre o outro "selvagem", que perturba o lugar sem fundar nenhum (CERTEAU 2008, p. 249), e o outro que sujeita e governa - talvez possa ser dada em termos de proximidade ou não a certo tipo de dominação. "Se há relações de poder em todo o campo social, é porque há liberdade em todo lado" (FOUCAULT 2006, p. 277), mas há configurações sociais nas quais se exerce uma violência ilimitada, um estado total de dominação. À exceção desses casos, estaríamos diante de sistemas de maior ou menor 
liberdade, onde as condições de resistência - fuga, subterfúgios, construções paralelas - estejam mais ou menos viáveis.

Construção de percursos. Elucidação das estratégias de controle. Condições de resistência. Possibilidades de consumo. Fundamentos de uma analítica que procure estabelecer as condições de constituição dos sujeitos em meio a saberes mais ou menos legitimados, a práticas que constituem os discursos ou Ihes escapam. No jogo extremamente dinâmico das estratégias e táticas, a construção de um modelo único com tais elementos é improvável. Mais profícuo, talvez, seja o delineamento de alguns pressupostos sem os quais um estudo dessa natureza não pode ser levado a cabo. Linhas gerais de um esboço metodológico impossível sem as contribuições de Foucault e Certeau.

\section{Pressupostos para um estudo das subjetividades}

Constituir o itinerário a partir do qual o indivíduo se torna sujeito (de uma conduta moral, de práticas pessoais, de resistência criativa) no âmbito de um espaço e período específicos é uma empreitada que, em Foucault e Certeau, foi realizada a partir de olhares diferenciados. O que está em ambos é a inviabilidade de proposição de um modelo único, que seria tão ficcional quanto o das narrativas unas, na medida em que se trata, na análise proposta por esses autores, de um olhar sobre as heterogeneidades e multiplicidades das práticas humanas.

Junto a essa compreensão subsiste outra, que dá conta de evidenciar os limites de nossas próprias ficções de pesquisa. A narrativa das práticas, pelo pesquisador, é em si uma prática (CHARTIER 1998), que também coloca em jogo as forças e enunciados que Ihe dão condições de existência. Termo intransponível, que testemunha continuamente nossa incapacidade de capturar plenamente os usos e as apropriações e nos coloca, como não poderia deixar de ser, no interior desse próprio jogo.

Parece, por outro lado, que a constituição de uma proposta analítica que tome como bases conceituais a produção foucaultiana e os pressupostos de Michel de Certeau teria, também, muito a contribuir no delineamento das condições históricas de constituição do sujeito. Será necessário, pois, realizar ao menos um tracejado inicial dos elementos que constituiriam, de maneira geral, um trabalho como esse.

Trata-se, em primeiro lugar, de uma analítica sempre contingente da história e do próprio sujeito. Um olhar, portanto, para as invenções sociais, que determinam os termos do indivíduo e não o inverso. Cada individualidade "é o lugar onde atua uma pluralidade incoerente (e muitas vezes contraditória) de suas determinações relacionais" (CERTEAU 2008, p. 38), e a constituição do percurso que a forma, tarefa sempre incompleta, é o que talvez possa melhor se aproximar de uma teoria da formação dos sujeitos. O "homem comum" é uma invenção, e destituí-la é uma atividade fundamental no âmbito das ciências humanas.

A pesquisa passa a ser, portanto, um exercício de verificação das condições de verdade, pelas quais se constituíram, de um lado, as possibilidades de construção de enunciações universais em um determinado momento histórico e, de outro, as fissuras a partir das quais tais verdades serão questionadas, 
desprezadas ou subvertidas pelas atividades cotidianas. A partir daí, verificar-se pois as regularidades de tais condições no espaço social, muito menos com a pretensão de se traçar um lugar comum e bem mais atento às conexões que possam se estabelecer entre práticas cotidianas paralelas (CERTEAU 1985), mas também entre os discursos que Ihe são próximos.

Em terceiro lugar, a análise constitui-se em uma perseguição à lógica (também contingente) das estratégias e táticas, em sua mobilidade e inversões. A produção estratégica se associa à constituição de seu próprio, que determina um lugar específico, uma visibilidade intensa e a primazia de um saber (CERTEAU 2008, p. 99). Na medida, porém, que a emergência do discurso (sempre estratégico) está também associada a uma apropriação dos saberes e práticas locais (uso dos usos), será necessária uma atenção quanto ao posicionamento dos enunciados e práticas cotidianas nas lutas que constituem a realidade estudada - muitas vezes encarnadas em "microrresistências que fundam microliberdades" (DURAN 2007, p. 118). No que se refere às práticas cotidianas, deve-se atentar ainda para a microfísica ${ }^{6}$ de seus procedimentos, que normalmente aparecem, no ambiente social estudado, "combinados segundo táticas ilegíveis mas estáveis a tal ponto que constituem regulações cotidianas e criatividades sub-reptícias" (CERTEAU 2008, p. 175). É fundamental, pois, determinar, no âmbito da analítica, os lugares/espaços onde se constituem tais estratégias - localizáveis, por exemplo, nas enunciações discursivas, nos procedimentos de governamentalização, em mecanismos disciplinares, normalizações éticas e emergências de saberes legitimados - e táticas - que se constituem nas resistências, golpes, apropriações ditas "ilegítimas", narrativas finitas, produções cotidianas etc.

Tal delimitação precisa considerar os modos diferenciados como operam os saberes, de acordo com seu posicionamento (espaço ou lugar que ocupa). Saberes legitimados, que estabelecem um objeto teórico, fundamentam a Ciência, constroem olhares periciais; saberes que operam na interioridade das relações, produzindo ações e afetos, constituindo olhares privados; saberes menos colonizados, que não constituíram seu próprio, e que vagueiam na forma de uma produção popular, em olhares menores; singularidades, saberes anônimos... Uma atenção ao discurso que é também ato, na consciência de que o objeto e seu uso constituem, juntos, o sujeito que, de alguma forma, (ou de forma nenhuma, talvez) deles se apropria.

Junto a uma analítica dos saberes, pois, constitui-se um olhar sobre as "maneiras de empregar", seja em âmbito estratégico ou tático. É provável que o consumo - não associado à construção de algo próprio, mas justamente ao que se faz com o que é apresentado ao sujeito - tenha, também, seu anticonsumo, na medida em que, do lugar das estratégias, também se constituem apropriações daquilo que outrora Ihe escapava. Seria assim com diversos movimentos sociais. Seria assim com os coletivos, ou com os espaços privados da internet. A heterogeneidade dos usos se deve às situações sociais e às relações de força

\footnotetext{
${ }^{6}$ Embora essencialmente foucaultiano, o conceito parece estar próximo das "práticas microbianas" de Certeau.
} 
que lhe circundam (CERTEAU 2008, p. 44) e, por isso, às configurações de poder que Ihe permeiam.

É necessário, pois, que tais usos sejam estudados no interior desses percursos complexos nos quais se inserem. Da mesma forma, o esforço parece ser o de apresentar as práticas e discursos em seus espaços próprios. Observar as práticas em seus jogos, nos relatos que Ihe constituem, na "arte de dizer" popular (CERTEAU 2008, p. 85); considerar os discursos em suas regras de formação, demarcando as superfícies de emergência, as instâncias de delimitação e as especificações dos objetos que produzem - compreendendo, pois, a operação que realizam (FOUCAULT 2008).

Encontrar o lugar do golpe, a antropofagia das práticas e as leis e regularidades a que se submetem (CERTEAU 2008). Nesse sentido, considerar que a própria narratividade é um golpe, e que o relato assume um papel central na constituição daquilo que pode ser apreendido pela observação analítica. Primeiro, naquilo que funda - a "arte de dizer" constitui espaços, forma mitos, descreve relações e, por isso, as cria. Em seguida, no que é capaz de cooptá-lo: as traduções, as formalizações, as legislações. Localizar as subversões do relatado é, na mesma medida, investigar as condições pelas quais ele se constitui em discursos credibilizados.

Verificar, enfim, as ficções. As utilizações compõem criações. As cooptações do cotidiano também as constituem. Será necessário, pois, que se verifiquem os produtos da luta, o que delas emerge como discurso, o que se populariza como resistência, compreendendo-se que, em todo caso, duas ficções parecem fundamentais e perenes nessa produção: a ficção da narrativa, capaz de produzir séries e inventar continuidades, e a ficção da memória, capaz de transformar surpresas em ocasiões. É possível, dessa maneira, perguntar-se como se consolidaria, por exemplo, o discurso acerca do homossexualismo, como as práticas e os movimentos viriam a operar no interior dos saberes constituídos e a maneira, como, novamente, seriam absorvidos em grandes passeatas e, daí, em produtos comercializáveis e ações governamentais. Ou compreender a maneira pela qual as práticas religiosas se apresentam e, em sua multiplicidade, sofreriam intensos investimentos, localizados, na construção de um discurso ecumênico que, ao mesmo tempo, as reduz e as relativiza em um culto generalizado.

Itinerários, aproximações e produções. Em seus diversos aspectos, a atividade do pesquisador se assemelha a do biólogo que esboça os aspectos de uma coevolução, ${ }^{7}$ dessa vez entre discursos e práticas. Percursos compartilhados, que por vezes evidenciam o embate das relações antagônicas e, em outros momentos, a produtividade das apropriações. No cerne dessa analítica, está a proposição de se considerar o movimento das estratégias e táticas sem abdicar, no entanto, da análise do discurso que Ihe possibilita e, igualmente, dos objetos que são, a partir dessas lutas, constituídos. A hipótese 
dessas linhas é, portanto, a de que a formação do sujeito se dá na relação entre os objetos e os usos que deles se faz; no contato entre os discursos e as práticas que a eles se somam ou se contrapõem. A maneira como os saberes (universais ou cotidianos) se constituem e são questionados, como se realizam as apropriações ou como se procura ou não resistir a determinados enunciados-práticas evidenciariam, pois, a dinâmica a partir da qual, naquele contexto, as subjetividades seriam constituídas. Assim, no que tange à constituição de objetos, seria possível surpreender tal produção subjetiva a partir de sua legitimação estratégica, materializada por meio de instituições e enunciados universais, ou de sua constituição tática, por meio das memórias e narrativas pessoais, por exemplo; do mesmo modo, no que se refere às modalidades de uso, parece plausível o olhar sobre suas formas estratégicas, como no caso dos movimentos de governamentalização e de dominação, ou táticas, visíveis em práticas cotidianas e relatos de experiências, para ficarmos apenas em algumas possibilidades analíticas.

Subjetivação nascida de uma polêmica que em alguns aspectos se diferencia da observação sobre os usos e daquelas dedicadas à análise do discurso. Como ferramenta, um tipo de analítica que redefine o posicionamento das produções táticas e das construções estratégicas nos termos cambiantes da utilização e da construção de objetos. Em seu interior, a compreensão de que o sujeito, esse constructo moderno, viu-se obrigado a abandonar os estabelecimentos universais de sua essência e se constituir na heterogeneidade das contingências históricas, nos diversos espaços e lugares de seu estabelecimento.

\section{Incursões finais}

Poder(es). Saber(es). Sujeito(s). Entre eles, produtividades, muitas vezes, incoerentes, em diversos momentos, descontínuas, mas sempre eficazes se considerarmos que individualidades se constituem a partir de suas relações. A questão que se coloca como central nos estudos foucaultianos - desse sujeito que se constitui no interior de um espaço moral, sob relações de conhecimento e ações - é também a que perpassa, por outra via, as reflexões de Michel de Certeau. Na aproximação de ambos os estudos, algumas evidências de que um olhar que se baseie na contribuição dos dois autores pode abrir novas possibilidades de análise.

Ao reposicionar a questão do governo - por meio de um duplo movimento que, de um lado, o desinstitucionaliza, colocando-o também no interior das relações entre indivíduos e, de outro, rende ao Estado um olhar que o considera como sistema capaz de se apropriar dos saberes locais - Foucault abre espaço para se considerar, sob outra ótica, os espaços de luta entre estratégias e táticas. Observadas no interior das relações cotidianas, as tentativas de governo dos indivíduos pelos indivíduos colocariam os espaços táticos e os lugares estratégicos em uma proximidade cotidiana ainda mais intensa do que aquelas atribuídas na crítica certeauniana, deslocando as possibilidades de "apropriação" para ambos os lados. Em complementação, as técnicas de governamentalização colocariam as racionalidades do Estado 
nos interstícios do jogo, evidenciando que a constituição de identidades e discursos nacionais pode também se beneficiar, de diferentes modos, das táticas que "vêm de baixo".

A dissipação do poder em uma microfísica parece particularmente profícua para colocar as estratégias e táticas, de fato, em um jogo, obrigando-nos a analisar a ambas, profundamente, naquilo que as forma e naquilo que, a partir delas, se produz. Encontrando as relações de poder na cotidianidade - tornando-nos, pois, delas incapazes de escapar - Foucault também abre espaço, aqui se aproximando muitíssimo da obra certeauniana, para o exercício de liberdades nos pequenos espaços das relações locais. Enxergar as possibilidades de subjetivação nas mais ínfimas porções da rede social é também tornar possível que, nesses pequenos espaços, se deem as resistências e criações.

Em Certeau, a possibilidade de se encontrar, analiticamente, os resultados cotidianos que, respondendo ou não às formalizações dos grandes enunciados, viriam a formar não-lugares, espaços móveis e inabitáveis que por vezes escapariam ou fariam trilhas paralelas aos mecanismos de controle. Com seu olhar sobre as estratégias e táticas, a possibilidade de constituir os lugares daqueles que operam com o poder ultrapassando a analítica estática das classes sociais e a compreensão, também reduzida, de que as lutas sociais se dariam, apenas, em termos econômicos de manutenção de capital.

Entre analíticas acerca da memória, da leitura e da escrita, das (anti-) disciplinas ou das visibilidades, Certeau verificou aquilo que Foucault anunciava, mas de que pouco se aproximou; esse, por sua vez, analisou aquilo que a produção certeauniana, então, faria ranger. Em ambos, um meticuloso trabalho que desmantelaria lugares estáveis e arrancaria do sujeito a universalidade de uma essência. Sob alguns aspectos, olhares complementares; em outros, antagonismos profundos. Na força mais uma vez evidente das polêmicas, a possibilidade de esboçar paralelismos, de inventar outros caminhos. Eis o sentido de uma proposta que, ao aproximar o genealogista do caçador, quis a ambos fazer reverência, sem deixar de lhes subverter.

\section{Referências bibliográficas}

CERTEAU, Michel de. A invenção do cotidiano: 1. Artes de Fazer. 15a ed. Tradução de Ephraim Ferreira Alves. Petrópolis: Vozes, 2008.

Teoria e Método no Estudo das práticas cotidianas. In: COTIDIANO, CULTURA E PLANEJAMENTO URBANO, 1985. Anais do Encontro Cotidiano, cultura popular e planejamento urbano. São Paulo: FAU/ USP, p. 3-19, 1985.

CHARTIER, Anne-Marie; HÉBRARD, Jean. A invenção do cotidiano: uma leitura, usos. Projeto História, n. 17, p. 29-41, 1998.

CHARTIER, Roger. Estratégias e táticas. De Certeau e as "artes de fazer". In: . À beira da falésia: a história entre certezas e inquietude. Porto

Alegre: Editora Universidade, 2002. 
DEFERT, Daniel. Cronologia. In: MOTTA, M. B. (org.). Ditos e Escritos 1: Problematização do sujeito: psicologia, psiquiatria e psicanálise. Rio de Janeiro: Forense Universitária, 2002, p. 1-70.

DURAN, Marília Claret. Maneiras de pensar o cotidiano com Michel de Certeau. Diálogo Educ., v. 7. n. 22, p. 115-128, 2007.

DROIT, Roger Pol. Foucault, Michel: entrevistas. São Paulo: Graal, 2006.

FOUCAULT, Michel. A Arqueologia do Saber. $7^{a}$ ed. Rio de Janeiro: Forense Universitária, 2008.

A escrita de si. In: MOTTA, M. B. (org.). Ditos e Escritos 5: Ética, Sexualidade e Política. Rio de Janeiro: Forense Universitária, 2006, p. 144-162.

A ética do cuidado de si como prática da liberdade. In: MOTTA, M. B. (org.) Ditos e Escritos 5: Ética, Sexualidade e Política. Rio de Janeiro: Forense Universitária, 2006, p. 144 - 162.

A verdade e as formas jurídicas. Rio de Janeiro: NAU Editora, 2005 (a).

. História da Sexualidade 3: o cuidado de si. Rio de Janeiro: Graal, 2005 (b).

Microfísica do Poder. $20^{a}$ ed. Organização e Tradução de Roberto Machado. Rio de Janeiro: Graal, 2004.

O sujeito e o poder. In: RABINOW, P; DREYFUS, H. Michel Foucault: uma trajetória filosófica. Para além do estruturalismo e da hermenêutica. São Paulo: Forense Universitária, 1995.

FUTUYMA, Douglas. Biologia Evolutiva. $2^{a}$ ed. Ribeirão Preto: Sociedade Brasileira de Genética, 1997.

GUATTARI, Félix. Revolução Molecular: pulsações políticas do desejo. São Paulo: Brasiliense, 1985.

MACHADO, Roberto. Foucault, a ciência e o saber. Rio de Janeiro: Jorge Zahar Ed., 2006.

VEIGA-NETO, Alfredo. Foucault e a Educação. $2^{a}$ ed. Belo Horizonte: Autêntica, 2004. 